\title{
Constraining $P$-wave velocity variations in the upper mantle beneath Southeast Asia
}

\author{
Chang Li*, Robert D. van der Hilst, M. Nafi Toksöz \\ Department of Earth, Atmospheric, and Planetary Sciences, Massachusetts Institute of Technology, \\ 77 Massachusetts Ave., Cambridge, MA 02139, USA
}

Received 16 May 2005; received in revised form 26 September 2005; accepted 26 September 2005

\begin{abstract}
We have produced a $P$-wave model of the upper mantle beneath Southeast (SE) Asia from reprocessed short period International Seismological Centre (ISC) $P$ and $p P$ data, short period $P$ data of the Annual Bulletin of Chinese Earthquakes (ABCE), and long period $P P-P$ data. We used 3D sensitivity kernels to combine the datasets, and mantle structure was parameterized with an irregular grid. In the best-sampled region our data resolve structure on scale lengths less than $150 \mathrm{~km}$. The smearing of crustal anomalies to larger depths is reduced by a crustal correction using an a priori 3D model. Our tomographic inversions reveal high-velocity roots beneath the Archean Ordos Plateau, the Sichuan Basin, and other continental blocks in SE Asia. Beneath the Himalayan Block we detect high seismic velocities, which we associate with subduction of Indian lithospheric mantle. This structure is visible above the $410 \mathrm{~km}$ discontinuity and may not connect to the remnant of the Neo-Tethys oceanic slab in the lower mantle. Our images suggest that only the southwestern part of the Tibetan plateau is underlain by Indian lithosphere and, thus, that the upper mantle beneath northeastern Tibet is primarily of Asian origin. Our imaging also reveals a large-scale high-velocity structure in the transition zone beneath the Yangtze Craton, which could have been produced in multiple subduction episodes. The low $P$-wave velocities beneath the Hainan Island are most prominent in the upper mantle and transition zone; they may represent counter flow from the surrounding subduction zones, and may not be unrelated to processes beneath eastern Tibet.
\end{abstract}

(C) 2005 Elsevier B.V. All rights reserved.

Keywords: $P$-wave tomography; Crustal correction; Upper mantle; SE Asia

\section{Introduction}

Southeast Asia is a tectonically diverse and active region. Continental collision in the west and eastward retreating slabs of subducting lithosphere in the east set up a large-scale clockwise rotation (black arrows in Fig. 1). The major large-scale features produced by the collision and post-collisional convergence of the Indian

\footnotetext{
* Corresponding author. Tel.: +1 617324 0268; fax: +1 6172589697 .

E-mail address: changli@mit.edu (C. Li).
}

and Eurasian plates include the Tibetan Plateau, where the continental crust has approximately doubled in thickness (Molnar and Tapponnier, 1975; Tapponnier et al., 2001; Rapine et al., 2003). Offshore, oceanic lithosphere is predominantly of early Cenozoic age, and there is ongoing subduction of the Pacific, Philippine Sea, and Indo Australian plates beneath Eurasia (van der Hilst et al., 1991; Fukao et al., 1992; Widiyantoro and van der Hilst, 1996) with eastward slab roll back since Oligocene times (van der Hilst and Seno, 1993; Northrup et al., 1995). Between these active plate boundary zones the continental lithosphere was subjected to extension during early Cenozoic time (Tapponnier and Molnar, 1977; 


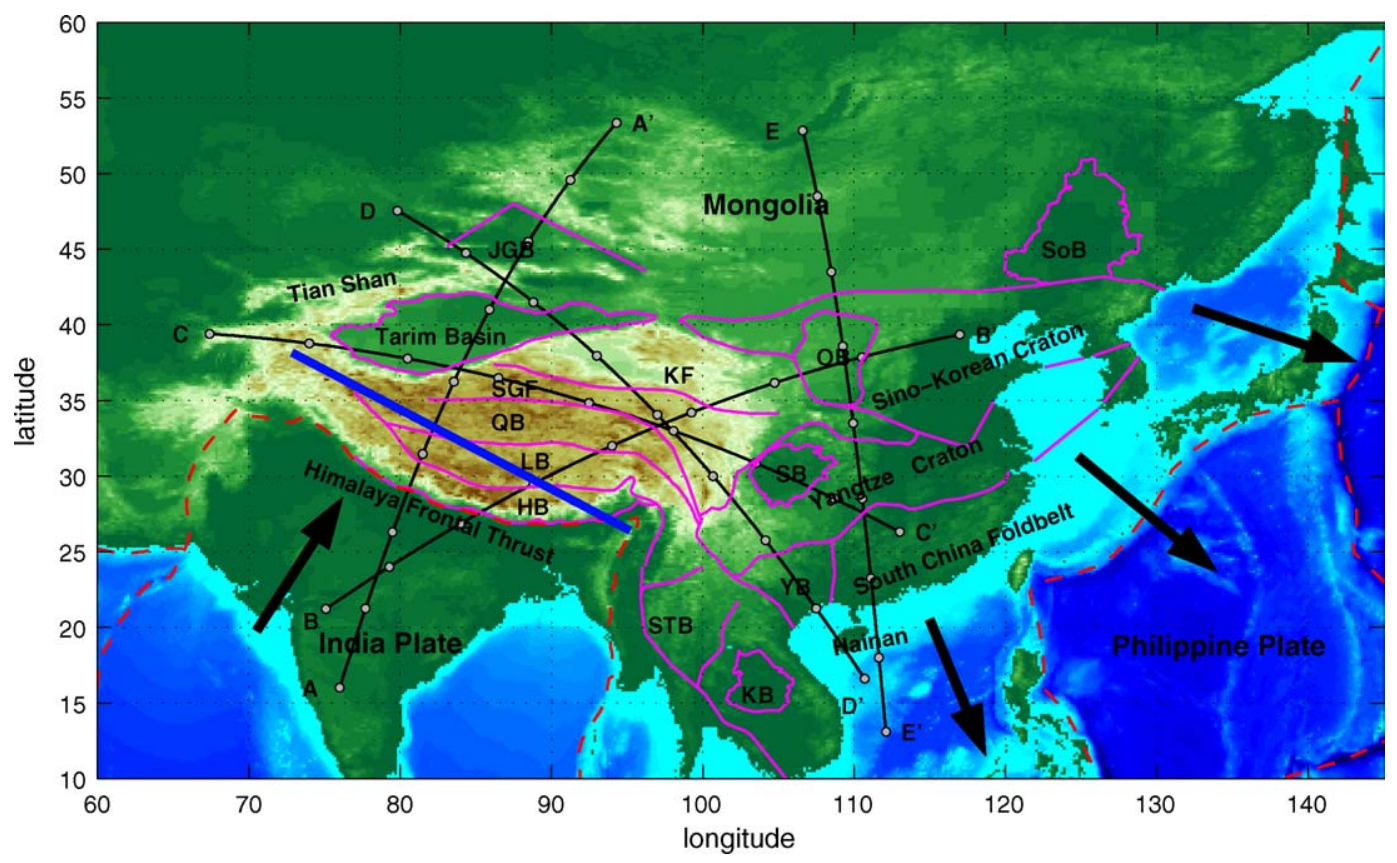

Fig. 1. The main tectonic elements in the SE Asia. The dashed red lines are plate boundaries, according to NUVEL-1 (DeMets et al., 1990). The thick purple lines denote main tectonic structures, where SoB-Songliao Basin, OB-Ordos Basin, SB-Sichuan Basin, KB-Khorat Basin, STB-Shan Thai Block, YB-Youjiang Block, JGB-Junggar Basin, SGF-Songpan Ganzi Foldbelt, QB-Qiangtang Block, LB-Lhasa Block, HB-Himalayan Block, KF-Kunlun Fault (modified from Li, 1998 and Tapponnier et al., 2001). Black arrows show the continental collision in the west and slab roll back in the east set up the clockwise rotation for the SE Asia. The blue thick line shows the horizontal limit of the Indian lithospheric mantle beneath the Tibetan plateau. The positions of five cross-sections in Fig. 9 are shown by black lines with grey dots.

Zhang et al., 1984; Li, 1998). The extensional features are usually regarded in the context of the Indian-Eurasian collision (Molnar and Tapponnier, 1975). However, both the collision and the subduction processes, along with their impact on mantle (return) flow beneath the region, must be taken into account in order to obtain a complete understanding of the dynamics and the tectonic evolution of SE Asia. It can be expected that this complex tectonics has produced significant structural heterogeneity in the upper mantle. Understanding this relationship is the main long-term objective of our study; here we present preliminary results of seismic travel time tomography.

Southeast Asia is characterized by relatively high levels of seismicity, but the distribution of seismological stations from which data are openly available is rather sparse (red triangles in Fig. 2). This puts restrictions on the type of seismic imaging that can be performed and the scale of the structure that can be resolved. Surface wave tomography studies show pronounced high-velocity continental roots beneath several Precambrian tectonic units (e.g., Ordos Plateau, Songliao Basin, Sichuan Basin) of SE Asia (Lebedev and Nolet, 2003; Debayle et al., 2005; Lebedev et al., 2005) and a seismically fast Indian lithosphere under southeastern Tibet
(Friederich, 2003). These features can also be inferred from global shear-wave velocity models (e.g., Trampert and Woodhouse, 1995; Ekström et al., 1997; Shapiro and Ritzwoller, 2002). However, the relatively low frequency of surface wave data put limits the structural wavelengths that can be resolved in the upper mantle.

In regions with good data coverage short-period travel times can provide higher resolution than the surface wave inversions. A number of $P$-wave tomographic studies have concentrated on complex morphology of the subducting oceanic lithospheric slabs beneath the western Pacific, the Philippine Sea, and Indonesia (e.g., van der Hilst et al., 1991; Fukao et al., 1992; Widiyantoro and van der Hilst, 1997). Using data from temporary seismic arrays, receiver function studies have focused on the crust and shallow mantle beneath central Tibet (e.g., Kind et al., 1996; Kosarev et al., 1999; Kind et al., 2002). Regional and local $P$-wave tomography has focused on the crust and uppermost mantle (e.g., Sun et al., 2004; Hearn et al., 2004; Liang et al., 2004; Huang et al., 2002; Wang et al., 2003). Global tomography has long been inadequate for detailed studies of the upper mantle beneath China and the broad realm of continental collision. In part this is due to the paucity of data 


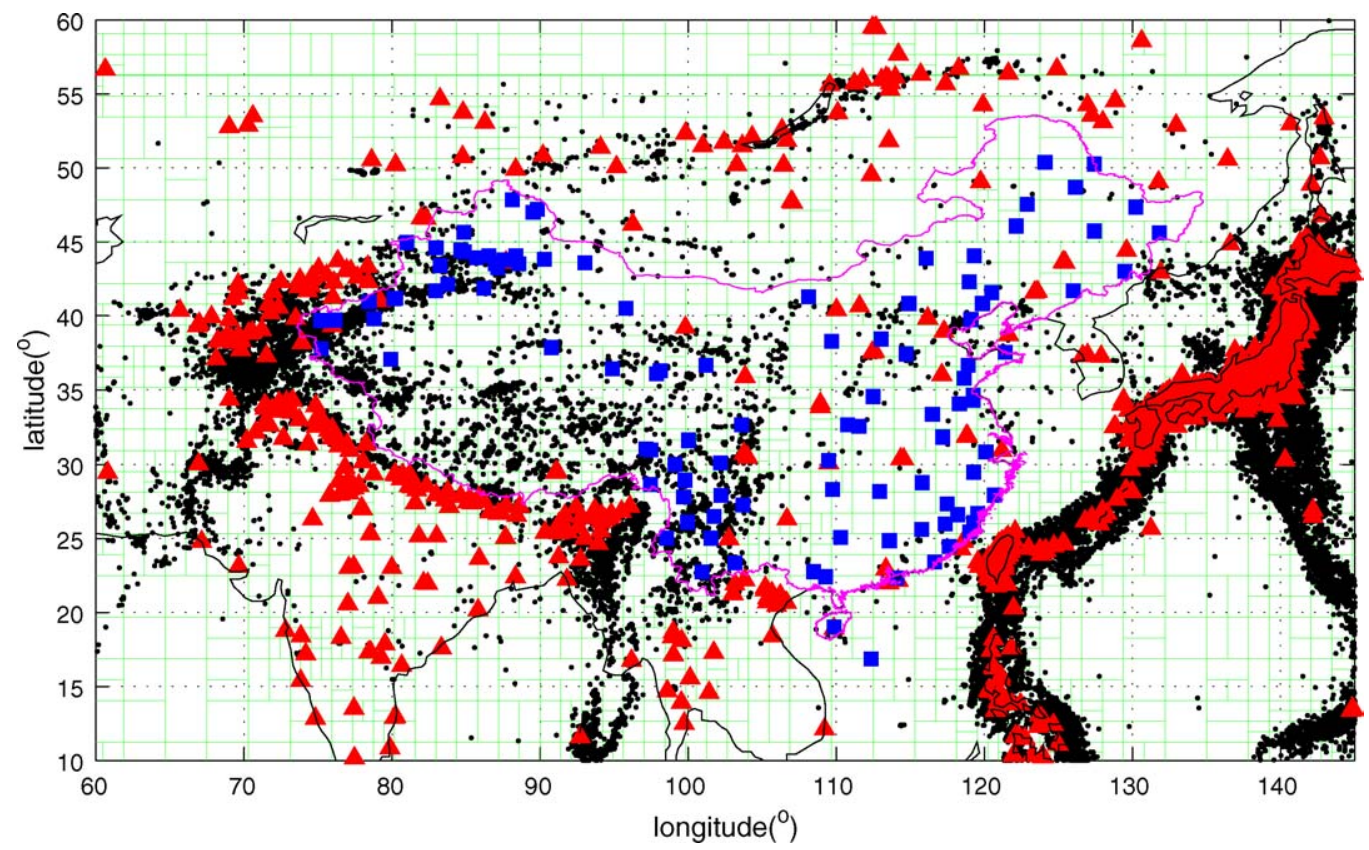

Fig. 2. The distribution of stations and earthquakes (black dots) in Southeast Asia and the irregular grids at $200 \mathrm{~km}$ depth. The irregular grid, depicted here with thin green lines for $200 \mathrm{~km}$ depth, allows us to resolve the fine structure in regions of dense sampling. Blue squares depict $107 \mathrm{stations}$ of $\mathrm{ABCE}$ from which data were not previously reported to ISC. Red triangles depict the $1223 \mathrm{EHB}$ stations in the area of interest, of which 44 stations are located in the mainland China.

from the numerous stations in China. But this situation is changing. There are promising signs that data from Chinese networks may become more openly available, and also data from temporary arrays will continue to fill in gaps in data coverage. For example, data from arrays deployed by MIT in collaboration with the Chengdu Institute of Geology and Mineral Resources (CIGMR), and by Lehigh University - CIGMR (Sol et al., 2004) are now being processed and will soon be incorporated into the inversions.

With a better $P$ wave velocity model of the upper mantle beneath Southeast Asia we hope to answer specific questions, for instance: How far does the Indian lithospheric mantle underthrust beneath the Tibetan plateau? What is the relationship between recent tectonic processes and structures deeper in the mantle? Which structures in the transition zone (TZ) are related to the underthrusting of Indian lithosphere and which are due to the subduction of the Pacific, Philippine Sea, and IndoAustralian plates? To improve the tomographic images of mantle structure in this region we (i) combine $P$ data from the Annual Bulletin of Chinese Earthquakes (ABCE) (a national earthquake catalog compiled by the Institute of Geophysics, China Seismological Bureau), $P$ and $p P$ data from Engdahl et al. (1998), and $P P-P$ differential travel time data from Bolton and Masters (2001); (ii) use an irregular grid parameterization to enhance local parameter estimation; and we (iii) correct for the large regional variations in crustal structure using an a priori 3D crustal model. As regards the latter, we present a simple approach that reduces artifacts caused by errors in the a priori crust models.

The results presented here are a subset of the new $P$ wave global model; compared to our previous results see, for instance, Kárason and van der Hilst (2001) - the use of an irregular grid, the addition of $P P-P$ and ABCE $(P)$ data, and the crustal corrections combine to provide more detail in the upper mantle region of our current interest. The global model will be presented elsewhere (van der Hilst, Li, and Kárason, in preparation) but is freely available upon request.

\section{Data}

The travel time data used in our study comes from three sources. The first is the International Seismological Centre (ISC) data that have been reprocessed by Engdahl et al. (1998) (hereinafter referred to as EHB). Engdahl et al. used arrival times reported to the ISC and calculated travel-time residuals using a non-linear process earthquake relocation and phase reidentification scheme. In our global inversion we used 
ca. 9,400,000 $P$ and 680,000 $p P$ EHB residuals of wellconstrained regional and teleseismic earthquakes that occurred between 01/01/1964 and 15/09/2004.

As a consequence of many Chinese stations not reporting to ISC the station coverage of EHB is not very good in SE Asia, especially in China. In order to improve data coverage, we augmented the EHB data with Annual Bulletin of Chinese Earthquakes (ABCE) data. This database contains nearly $670,000 P$-wave travel time residuals from 220 stations in China and surrounding areas. Combining datasets has to be done with care. Relative to the ak135 reference velocity model (Kennett et al., 1995), the ABCE residuals have an offset of more than $2 \mathrm{~s}$. There are two contributions to this baseline problem. One is the effect of crustal structure in the region. If the crust is thicker than that of the reference model the arrival time will be greater than the reference travel time, resulting in positive travel time residuals. For example, the $0.5 \mathrm{~s}$ offset at Lhasa station is most likely due, in part, to the thick crust of Tibet. We account for this in the inversion. The second and larger effect concerns the source locations used in the EHB and ABCE catalogs; they can differ substantially, in particular for events in the Wadati-Benioff zones beneath the northwest Pacific island arcs. Calculating the ABCE residuals with respect to the EHB hypocenters reduces the baseline to less than $0.2 \mathrm{~s}$. Prior to inversion we eliminated data for the $113 \mathrm{ABCE}$ stations that are already included in EHB. The study area comprises 1223 EHB stations (44 of which are mainland China, red triangles in Fig. 2) and 107 Chinese ABCE stations that have not been reported to ISC (blue square in Fig. 2).

The subset of the global model presented here also includes $\sim 22,000 P P-P$ low frequency differential times measured by waveform cross-correlation (Bolton and Masters, 2001). We account for sensitivity to structure away from the optical ray path with 3D Fréchet derivatives (sensitivity kernels) estimated from single forward scattering; for details see Kárason (2002) and van der Hilst et al. (in preparation). For the spatial resolution sought here these low frequency data may seem superfluous, but the $P P-P$ differential times constrain large wavelength variations in the region under investigation.

\section{Methodology}

\subsection{Adaptive grid}

Uneven data coverage can produce significant lateral variation in resolution of tomographic models. We mitigate effects of uneven data coverage by means of an adaptive parameterization based on the sampling density of the high-frequency data (Abers and Roecker, 1991; Bijwaard et al., 1998; Kárason and van der Hilst, 2000). Each block in the grid used in the inversion consists of one or more base blocks of $45 \mathrm{~km} \times 0.7^{\circ} \times 0.7^{\circ}$. The total number of free parameters (that is, the sampled irregular blocks and the event relocation parameters) is slightly less than 0.5 million. As an example, Fig. 2 (green lines) displays the irregular grid at $200 \mathrm{~km}$ depth. The relatively fine grid near the subduction zones of the Indian and Philippine Sea plates, the Sichuan Basin, and Tian Shan suggests that in these regions we can image finer structures. In contrast, the grids beneath Mongolia, the Tarim Basin, and the center of Philippine Sea is relatively coarse, which, of course, limits the spatial resolution beneath these regions.

For the calculation of the sensitivity matrix associated with short period data we use a high-frequency approximation and trace optical rays (in the radially stratified reference model). We use weighted composite rays (Kárason and van der Hilst, 2001) to better balance the sampling and further reduce the size of the sensitivity matrix. Because of noise in the data, we apply norm and gradient damping: norm damping favors a result that is close to the reference model and thus tends to minimize the amplitude of the model, while gradient damping reduces the differences between adjacent blocks and thus produces smooth variations, both laterally and radially. We perform experiments with synthetic data and known input models to find appropriate values for the damping parameters, but the choice of the parameters remains subjective. In our inversions, the norm damping is small. We use the iterative method LSQR (Paige and Saunders, 1982) to minimize

$\varepsilon=\|A m-d\|^{2}+\lambda_{1}\|L m\|^{2}+\lambda_{2}\|m\|^{2}$,

where $A$ is the sensitivity matrix, $d$ is the vector of travel time residuals, and $m$ is the vector of model parameters (which include slowness perturbations and hypocenter mislocations). $L$ is a smoothing operator, and $\lambda_{1}$ and $\lambda_{2}$ are the weights for gradient and norm damping, respectively. The results presented here were obtained after 200 iterations, but for LSQR most of the convergence is achieved within a small number of iterations: 98\% of the total variance reduction is obtained within the first 25 iterations. In order to visualize the values determined for the irregular blocks we projected and interpolated them on a regular $\left(0.5^{\circ} \times 0.5^{\circ} \times 50 \mathrm{~km}\right)$ grid.

\subsection{Crust correction}

The small incidence angles of the $P$-waves may combine with strong crustal heterogeneity to cause 
crustal anomalies to be 'smeared' (mapped) to larger depths in the model. This could be a significant problem if the actual crust is very different from that in the 1D reference model, as is the case here. Application of crustal correction in global surface wave tomography is common practice, see, e.g., Boschi and Ekström (2002), but such corrections are not yet routinely considered in regional and global travel time tomography.

In SE Asia, the lateral variation in crustal thickness is considerable. For instance, crust of the Tibetan plateau is at least $70 \mathrm{~km}$ thick compared to just several kilometers for the oceanic crust in the Philippine Sea (Fig. 3a, from $\left(59^{\circ} \mathrm{E}, 35^{\circ} \mathrm{N}\right)$ to $\left.\left(134^{\circ} \mathrm{E}, 14^{\circ} \mathrm{N}\right)\right)$. As an estimate of the 3D crustal structure we embed the regional model by Sun et al. (2004) into the global CRUST 2.0 (Bassin et al., 2000), calculate the difference in wavespeed with respect to $a k 135$, and project this a priori crustal model onto our grid (Fig. 3b). In order to evaluate if and how this crustal heterogeneity would "smear" into the model if unaccounted for, we use a resolution experiment with synthetic data. The response to such a crustal model,
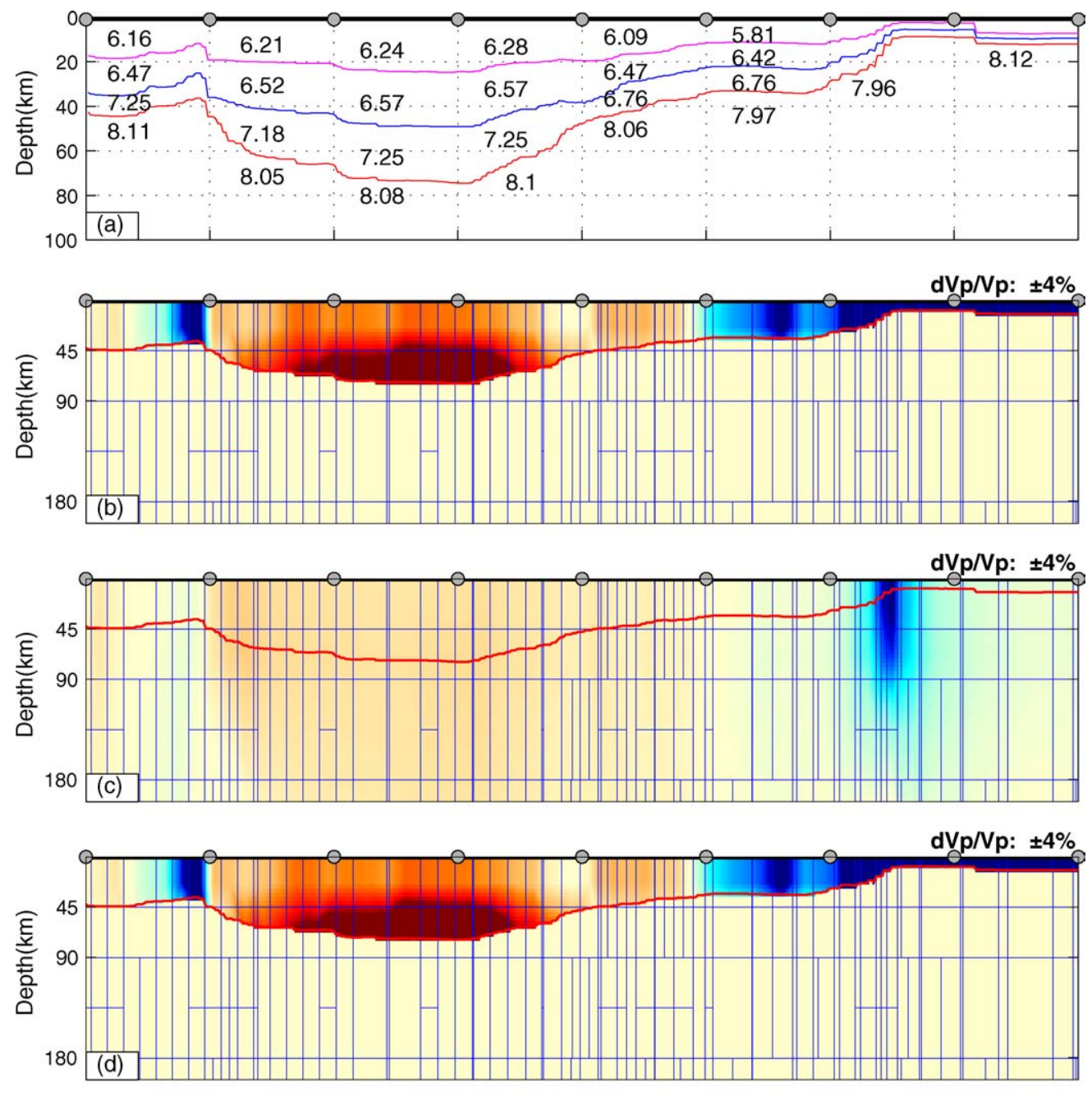

slow

fast

Fig. 3. Regularization for 3D crust. (a) Three layers of crust through the Tibetan plateau and Philippine Sea (from $\left(59^{\circ} \mathrm{E} 35^{\circ} \mathrm{N}\right)$ to $\left(134^{\circ} \mathrm{E} 14^{\circ} \mathrm{N}\right)$ ). $P$ wavespeeds of input model (in $\mathrm{km} / \mathrm{s}$ ) for each layer is shown. (b) Vertical projection of 3D crust on irregular grid. (c) The recovery model using same inversion scheme and sampling as in the construction of the final model. (d) The recovery model using the regularization in the model space for crust. After regularization, the big velocity variation of the crust can be confined in crustal blocks. Moho depth (red line) and irregular grid (blue line) are shown in b, c, and d. 
including all its artifacts, is shown in Fig. 3c. Obviously, the crust cannot be resolved by the data used, and crustal structure may be smeared to depths of at least $200 \mathrm{~km}$. Moreover, the retrieved anomalies are much smaller than those in the input models. We try to remedy this with a crustal correction.

Crustal corrections can be done in several ways. One could calculate travel times through the 3D crustal model, subtract these from the observed times, ray-trace to the bottom of the 3D crust, and then solve for the structure beneath the crust while leaving the crustal model unchanged (e.g., Waldhauser et al., 2002; Weidle and Widiyantoro, 2005). While straightforward and intuitive, without an explicit method for confining crustal anomalies to the crust, the relatively large anomalies of the 3D crust can still smear into the upper mantle. Moreover, artifacts due to errors in the crustal models are not mitigated. A practical drawback is that later data addition and (crustal) model updates require repeated ray tracing, which comes at considerable computational cost. Furthermore, calculating explicit time corrections is not straightforward for phases with complicated sampling properties, such as $P P$.

In view of these disadvantages, we correct for crustal structure by means of regularization; this is accomplished through a simple modification of (1):

$$
\begin{aligned}
\varepsilon= & \|A M-d\|^{2}+\lambda_{1}\|L M\|^{2}+\lambda_{2}\|M\|^{2} \\
& +\lambda_{3}\left\|C-M_{\mathrm{c}}\right\|^{2},
\end{aligned}
$$

where $C$ is the a priori $3 \mathrm{D}$ crustal model and $M_{\mathrm{c}}$ is the crustal part of the model space $M$. We determine $\lambda_{3}$ through tests with synthetic data. Through such regularization in the model space we can balance the crust and upper mantle contribution to misfit $\varepsilon$ and recover the a priori crustal model (Fig. 3d). Later addition of data sets does not require further calculations since all is accounted for in the model space.

These methods of crust correction produce the same result, but because of the ease of implementation we use the regularization approach for the inversions discussed below.

\section{Results}

\subsection{Model improvements}

The addition of the ABCE data and the correction for the crust improve the 3D mantle model (Fig. 4). For 60 and $200 \mathrm{~km}$ depth, Fig. 4A (1 and 2) depicts the model derived from the EHB and PP data. The addi- tion of the $\mathrm{ABCE}$ data, and concomitant adjustment of the grids, increases our ability to resolve the small-scale structure (Fig. 4B1 and B2). In the mainland of China, where the extra $\mathrm{ABCE}$ stations are located, more detail is recovered than before. For example, we now begin to observe a high-velocity structure beneath the eastern part of the Sichuan Basin and the Songliao Basin and a low velocity structure beneath the Songpan Ganzi Foldbelt (Fig. 4B1 and B2). As expected, outside the mainland of China, for instance beneath the Indian continent and the Philippine Sea, the improvements are small. The crustal thickness of central Tibet $(\sim 70-90 \mathrm{~km})$ differs significantly from the $35 \mathrm{~km}$ in $a k 135$, but the application of our crust correction reduces the smearing of unresolved shallow structures (compare, e.g., Fig. 4C2 and B2).

\subsection{Resolution tests}

Resolution test with synthetic data confirm that the addition of the $\mathrm{ABCE}$ data increases our ability to resolve 3D structure. In Figs. 5 and 6 we show the retrieved structure from a checkerboard resolution test at different depths for box sizes of $5^{\circ} \times 5^{\circ}$ and $3^{\circ} \times 3^{\circ}$, respectively. The input structure of $\pm 1 \%$ velocity variation (Figs. 5.0 and 6.0) was computed one layer at a time, and noiseless synthetic travel times were created and inverted using the same inversion scheme and sampling (that is, sensitivity matrix) as used in the inversion of the earthquake data. In the shallow mantle, spatial resolution remains a concern. At 200 and $300 \mathrm{~km}$ depth the pattern is smeared beneath Philippine Sea, South China Sea, and most of Mongolia, but in areas of our particular interest, such as mainland China, and the Himalayas the recovery is somewhat better (Fig. 6.3 and 6.4). The $5^{\circ} \times 5^{\circ}$ pattern can be recovered beneath China (Fig. 5.1 and 5.2), but smaller anomalies are not likely to be resolved beneath the Tarim Basin and the northern part of Tibet (Fig. 6.1 and 6.2). At depths below $400 \mathrm{~km}$, both the $5^{\circ} \times 5^{\circ}$ and $3^{\circ} \times 3^{\circ}$ input patterns are recovered beneath most parts of our study region (Figs. 5.5-5.9 and 6.5-6.9).

The near vertical incidence of rays reduces the radial resolution in the shallow mantle. The checkerboard tests of two input patterns $(400 \mathrm{~km} \times 400 \mathrm{~km}$ and $280 \mathrm{~km} \times 280 \mathrm{~km}$ ) in Fig. 7 help us evaluate the vertical resolution of structure in the five slices that will be discussed later. These slices are about $4000 \mathrm{~km}$ long and extend from Earth's surface to $1700 \mathrm{~km}$ depth. In general, the recovery of the input models is adequate below $400 \mathrm{~km}$ depth. At shallower depth, small-scale structure cannot be recovered well in many areas beneath the study 

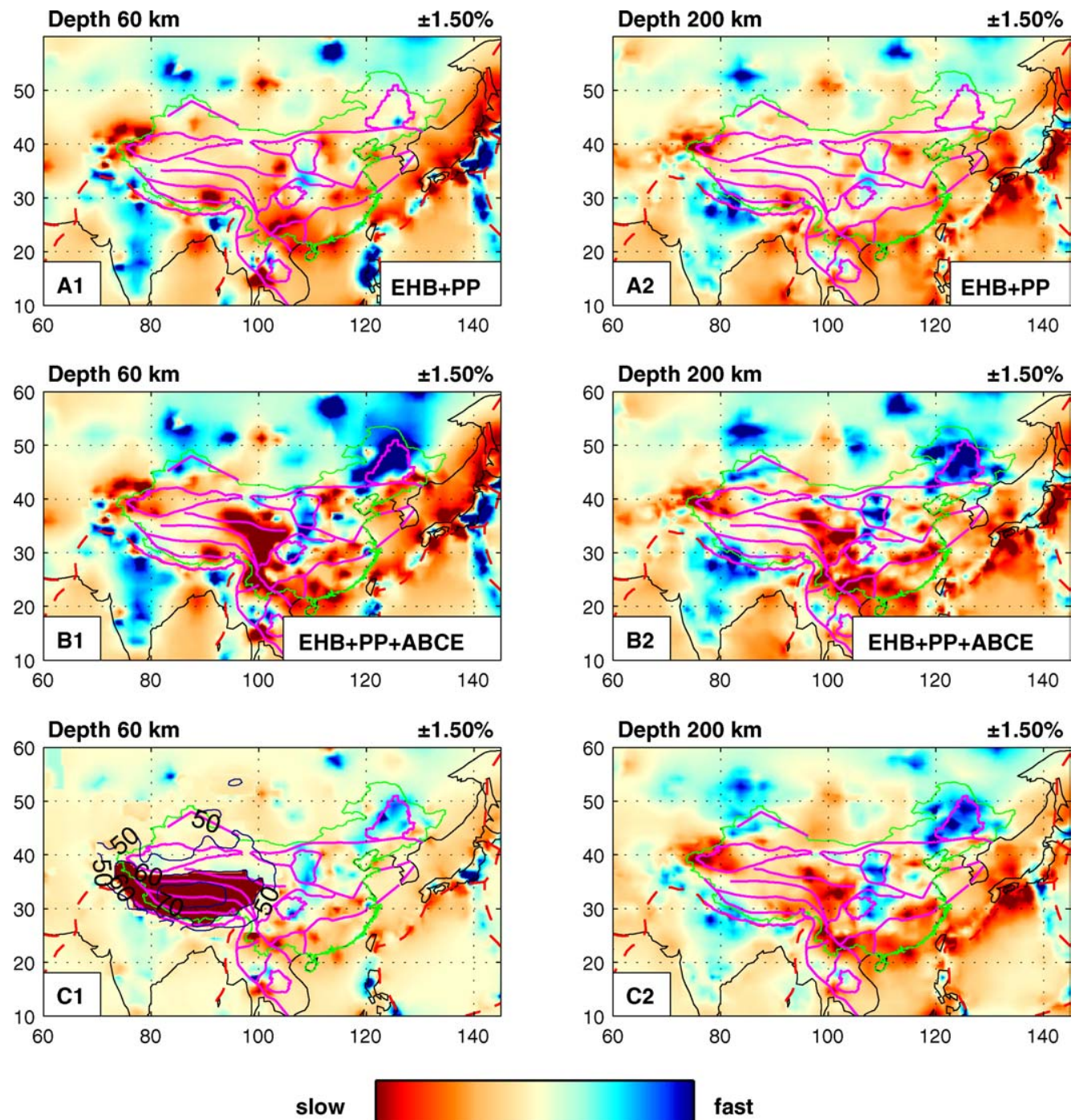

Fig. 4. Effects of data addition and crust correction; for illustration purposes we only display the models at 60 and $200 \mathrm{~km}$ depth. (A) Model based on EHB and $P P$ data only. (B) $\mathrm{EHB}+\mathrm{PP}+\mathrm{ABCE}$ data. (C) $\mathrm{EHB}+\mathrm{PP}+\mathrm{ABCE}+3 \mathrm{D}$ crust correction. Regularization in the model space not only recovers the big anomaly in the crust, it can also balance the crust and upper mantle to best fit the travel time residuals. $\mathrm{C} 1$ depicts the 50,60 , and $70 \mathrm{~km}$ depth contours of the 3D crust model used; within these contours the wavespeed is much lower than in the reference values (ak135), see Fig. 3b.

region, but larger scale variations can be recovered reasonably well.

From our lateral checkerboard test we conclude that below $200 \mathrm{~km}$ depth most of the $3^{\circ} \times 3^{\circ}$ input signal could be recovered, so the average resolution length at these depths is the half of input signal dimension (Lebedev and Nolet, 2003), that is, about $150 \mathrm{~km}$. At shallow depths, the smaller scale pattern is only recovered beneath a few densely sampled regions, such as the Yangtze Craton, the Sino-Korean Craton, and the Himalayas (Fig. 6.1), where we estimate the resolution length to be of the order of $100 \mathrm{~km}$. At the Tarim
Basin and the north part of Tibet, the estimated lateral resolution is ca. $200 \mathrm{~km}$ (Fig. 6.2). The vertical resolution length is about $150 \mathrm{~km}$ below $400 \mathrm{~km}$ depth (Fig. 7).

\subsection{Structure of the upper mantle beneath SE Asia}

We show the $P$-wave velocity variations in map view from the surface to about $700 \mathrm{~km}$ depth (Fig. 8) and in five vertical cross-sections (Fig. 9). For presentation purpose we label the major structures as 1, 2, 3 and so on. The major features of the model are discussed below. 

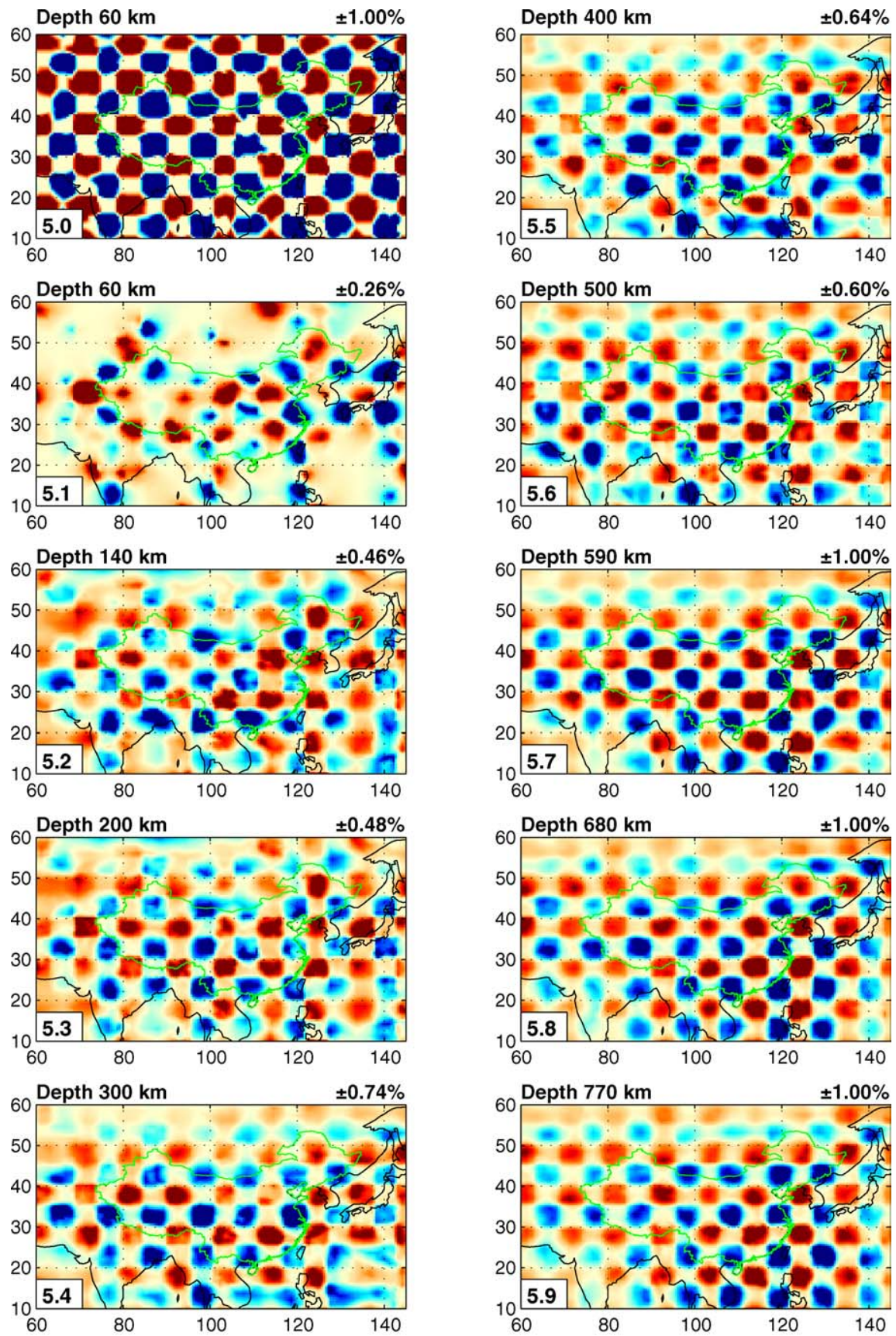

slow

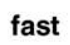

Fig. 5. Checkerboard resolution test for target anomalies at different depths. Input pattern $\left(5^{\circ} \times 5^{\circ}\right)$ is shown in 5.0.

\subsubsection{Upper mantle structure beneath India and central Tibet}

A pronounced high-velocity anomaly (labeled as 1) is visible to a depth of $\sim 300 \mathrm{~km}$ beneath the region of the Precambrian Indian continent (Fig. 8a-d). In cross-section this structure appears to dip northeastward with the flexure starting near the foreland basin about $200 \mathrm{~km}$ to the south of the Himalaya Frontal Thrust 

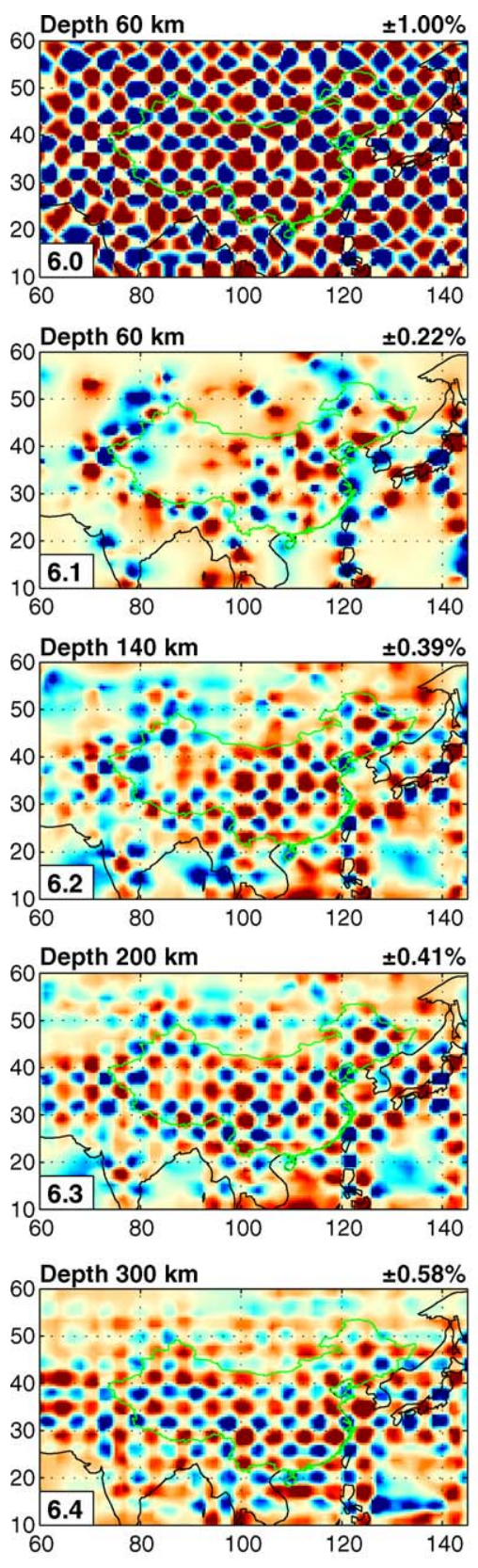

slow
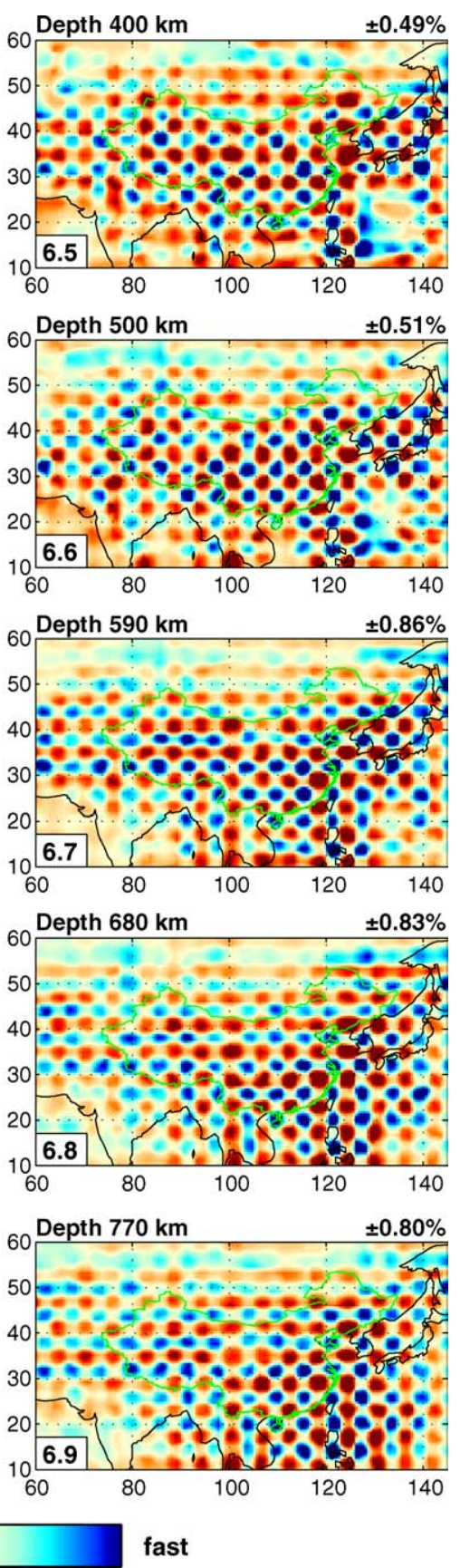

Fig. 6. Checkerboard resolution test for target anomalies at different depths. Input pattern $\left(3^{\circ} \times 3^{\circ}\right)$ is shown in 6.0.

(Figs. 1 and 9a). Even though it is not yet well resolved, we interpret this dipping structure as the subducting slab of Indian continental lithosphere, and perhaps part of the Tethyan oceanic lithosphere in front of it. From Figs. 8b-e and 9a we infer that only the southwestern part of the Plateau, the Himalayan Block and the western Lhasa Block, is directly underlain by the Indian litho- sphere, the northern limit of Indian lithosphere beneath Tibet is marked by the thick blue line in Fig. 1. Our result is consistent with the image presented by Shapiro and Ritzwoller (2002), but since they used fundamental mode surface waves they could only map the structure to ca. $200 \mathrm{~km}$ depth. In our images the dipping structure is detected to at least $400 \mathrm{~km}$ depth, and possibly 


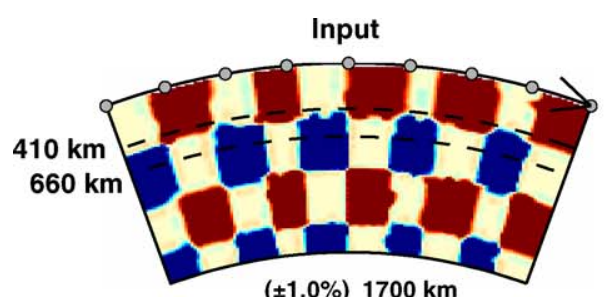

$( \pm 1.0 \%) 1700 \mathrm{~km}$
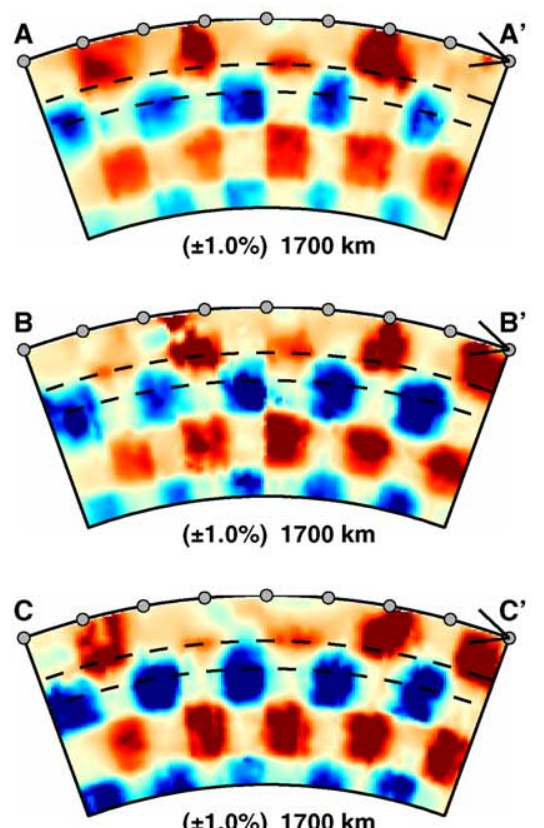

$( \pm 1.0 \%) 1700 \mathrm{~km}$
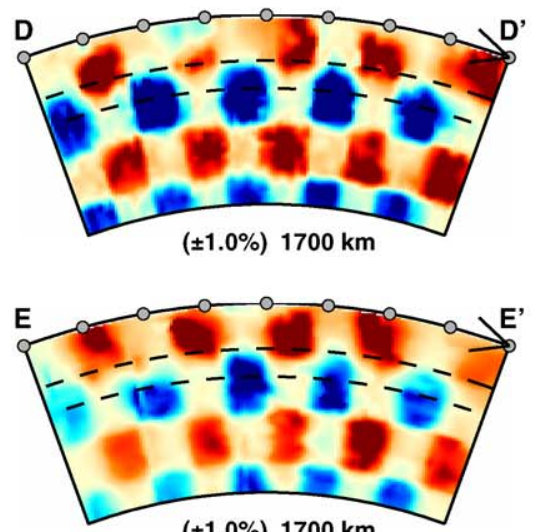

$( \pm 1.0 \%) 1700 \mathrm{~km}$

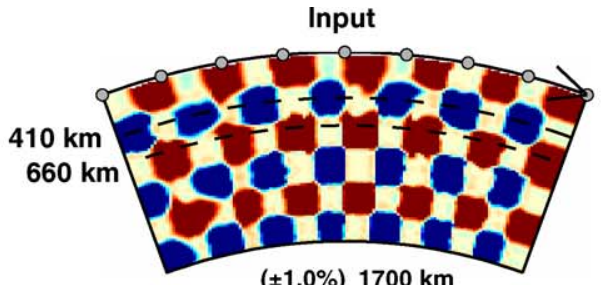

$( \pm 1.0 \%) 1700 \mathrm{~km}$
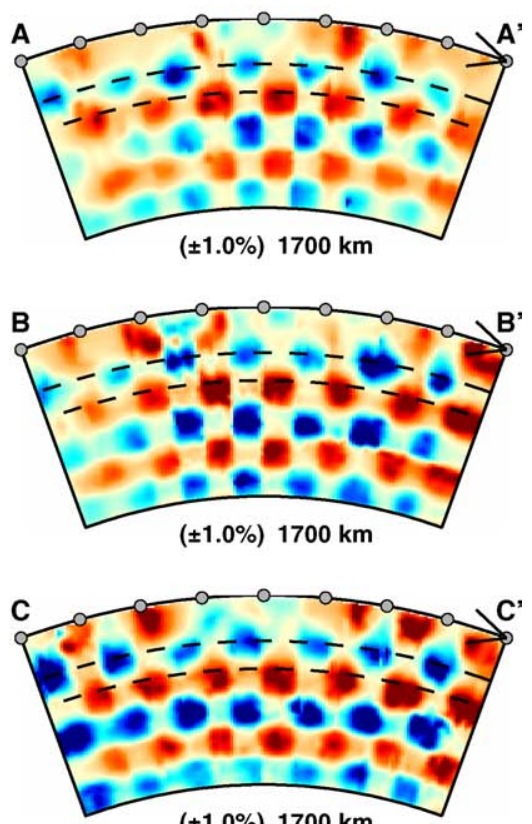

$( \pm 1.0 \%) 1700 \mathrm{~km}$
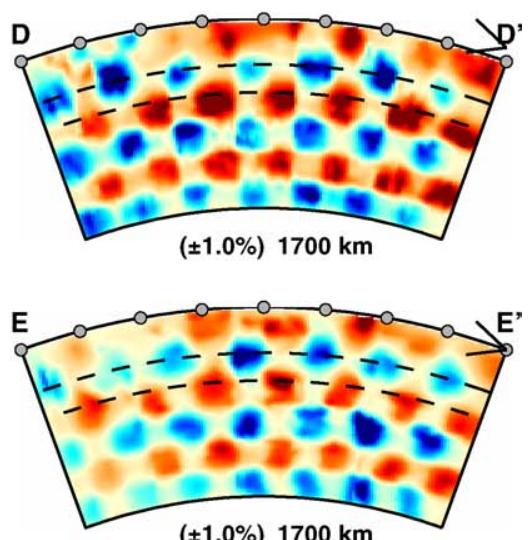

$( \pm 1.0 \%) 1700 \mathrm{~km}$

slow

fast

Fig. 7. Vertical checkerboard resolution tests at five slices, as depicted in Fig. 1. For each slice we use the same input pattern (show at the top) with target anomalies of $400 \mathrm{~km} \times 400 \mathrm{~km}$ (left) and $280 \mathrm{~km} \times 280 \mathrm{~km}$ (right).

continues to $\sim 660 \mathrm{~km}$ depth. At depths greater than about $660 \mathrm{~km}$ another high-velocity anomaly is observable beneath north-central India (structure 2 in Fig. 8h). In Fig. 9a, this structure extends just near the $660 \mathrm{~km}$ discontinuity to deep in the lower mantle with a southdipping angle, where it forms part of the large scale structure that has been interpreted as a remnant slab of late Mesozoic Tethys oceanic lithosphere prior to the 

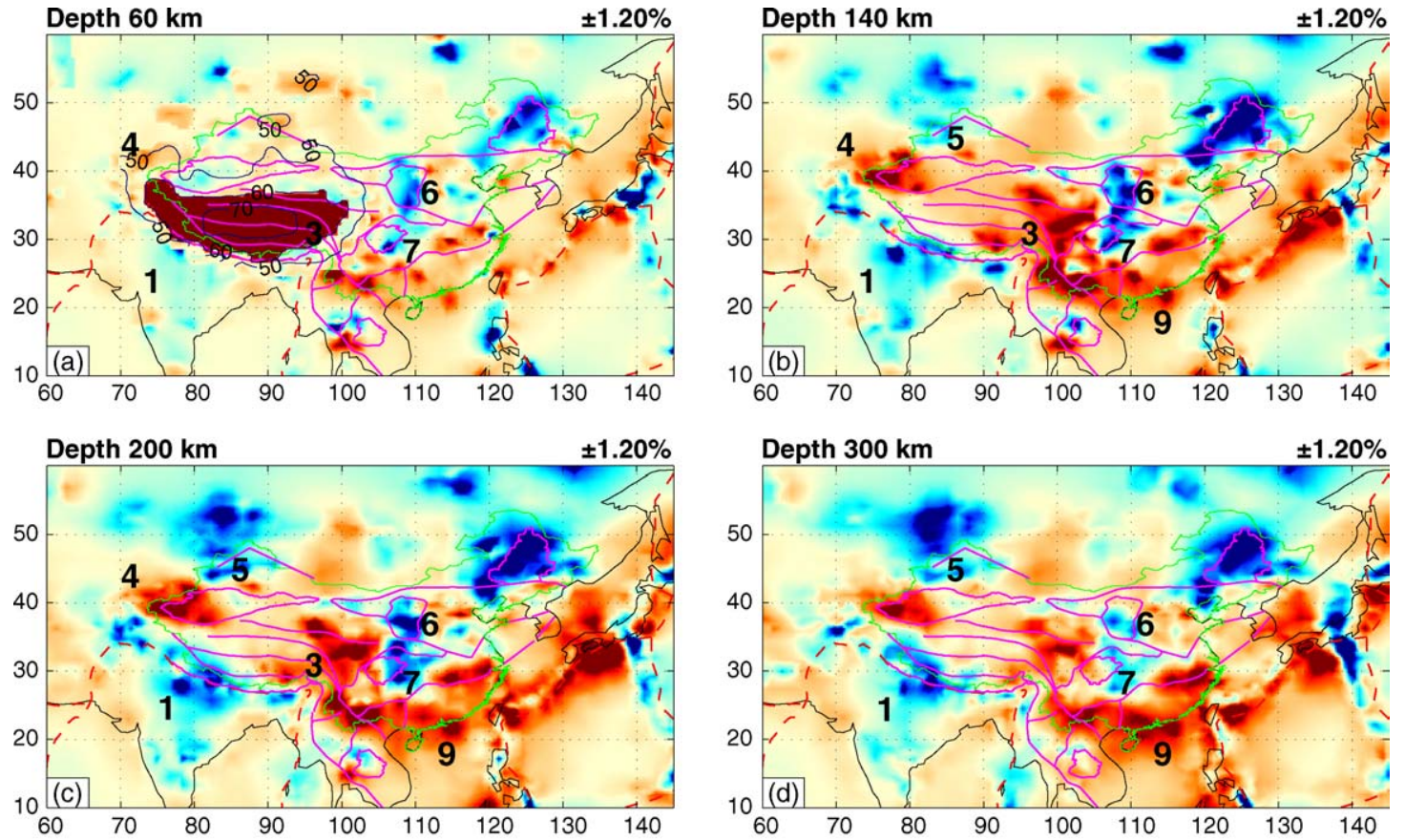

slow

fast
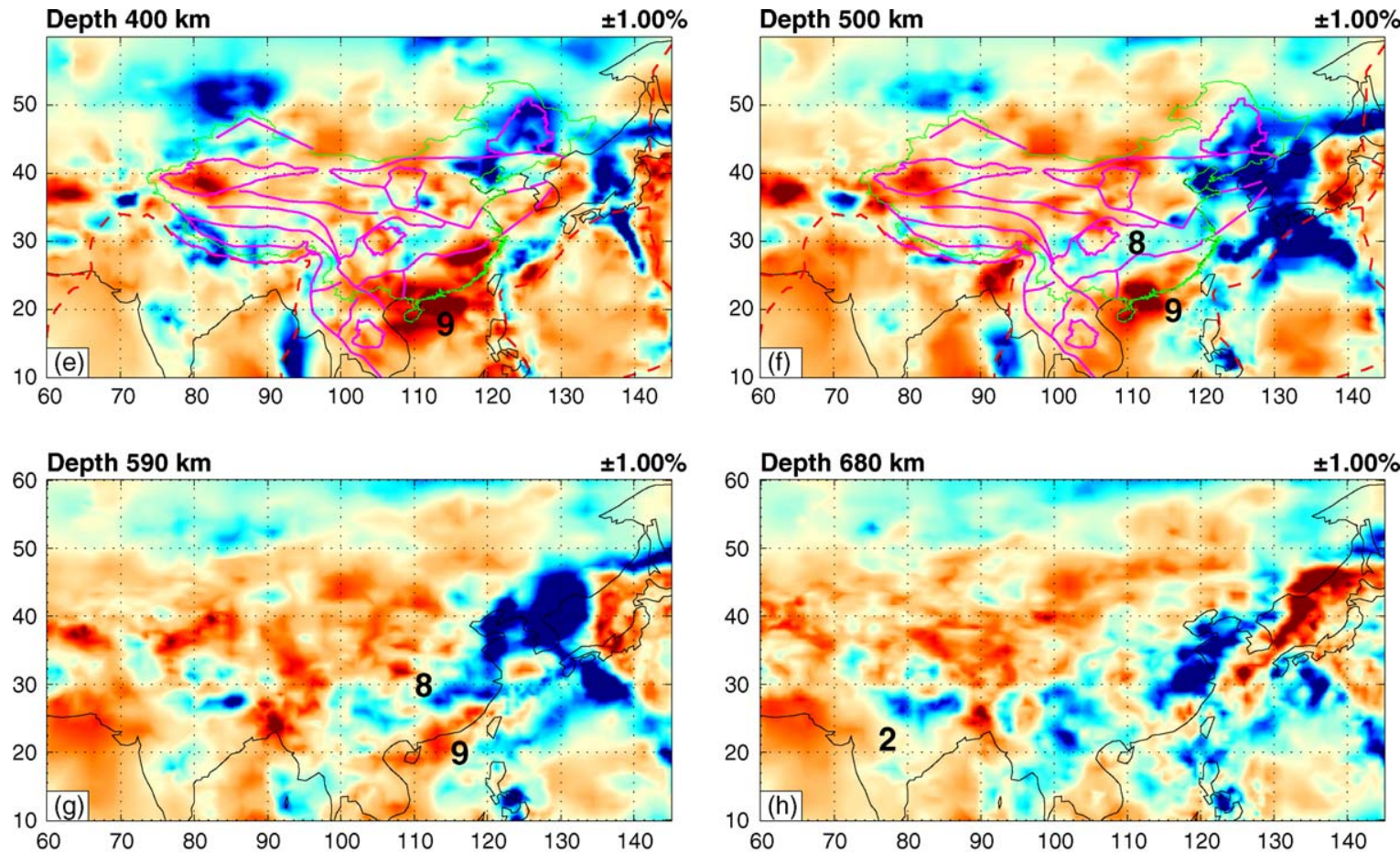

slow

fast

Fig. 8. Lateral $P$ wavespeeds perturbation at different depths as indicated on the left corner. The blue and red represent fast and slow perturbation, respectively. The perturbation scale is shown on the right upper corner. The significant structures have labeled as 1,2, 3, etc. 


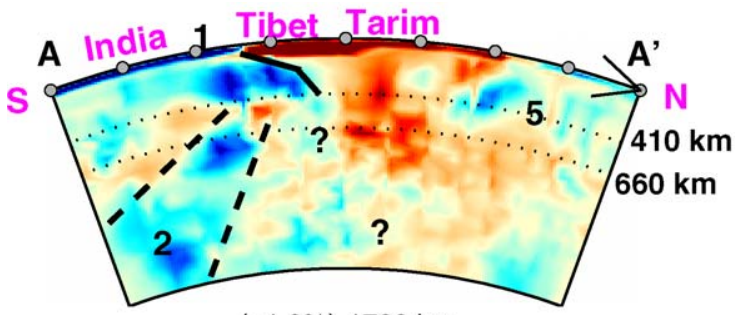

$( \pm 1.0 \%) 1700 \mathrm{~km}$

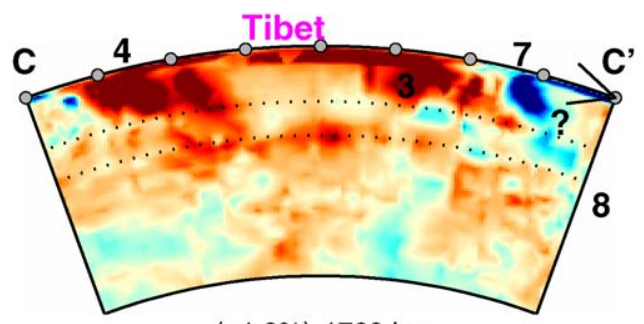

$( \pm 1.0 \%) 1700 \mathrm{~km}$

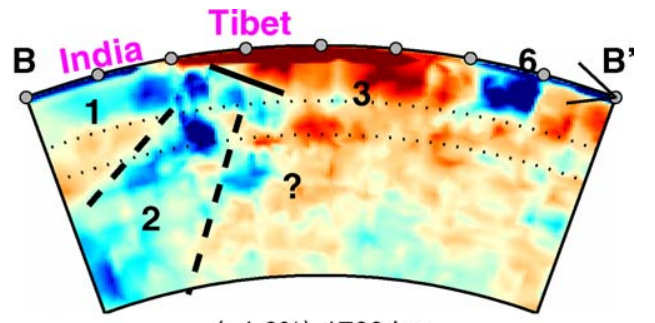

$( \pm 1.0 \%) 1700 \mathrm{~km}$

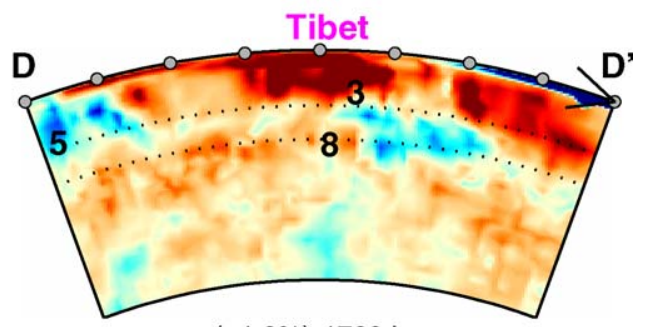

$( \pm 1.0 \%) 1700 \mathrm{~km}$

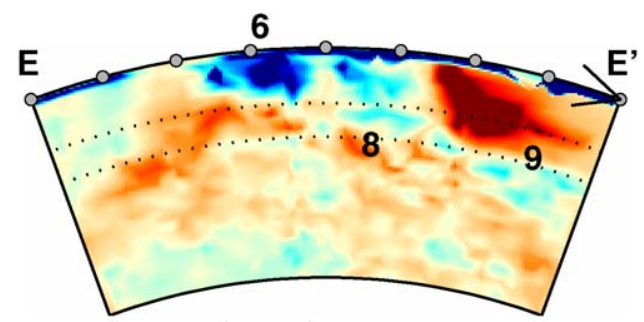

$( \pm 1.0 \%) 1700 \mathrm{~km}$

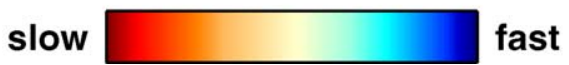

Fig. 9. Vertical cross-sections through some of the main features of the velocity model down to $1700 \mathrm{~km}$ depth. The locations of cross-sections AA', $\mathrm{BB}^{\prime}, \mathrm{CC}^{\prime}, \mathrm{DD}^{\prime}$, and $\mathrm{EE}^{\prime}$ are indicated in Fig. 1.

India-Eurasia collision (van der Hilst et al., 1997; Van der Voo et al., 1999; Replumaz et al., 2004). The spatial resolution of the current data coverage does not yet allow us to establish the structural relationship between the northward dipping structure 1 and the southward dipping structure 2 .

\subsubsection{Upper mantle structure beneath eastern Tibet}

Our results suggest that the shallow mantle beneath the southeastern part of Songpan Ganzi Foldbelt and eastern parts of the Tibetan Plateau is marked by very slow $P$ wavespeeds (structure 3 in Fig. 8b). The wavespeeds would be artificially low if the actual crust is even slower than that in the a priori model used, but the resolution of shallow mantle structure is adequate (Fig. 6.2-6.4) so that leakage to large depths is unlikely. The slow velocity structure continues to $300-400 \mathrm{~km}$ depth (Figs. 8b-d and 9d). These results suggest that this slow velocity structure extends beyond the eastern margin of Tibet and to depths well in excess of the thick crust. In fact, our images suggest that these slow structures connect to the slow wavespeeds in the upper mantle beneath South China Sea coast and, in particular, Hainan Island (Fig. 8d-e).

\subsubsection{Tian Shan and Tarim basin}

Slow velocities beneath the Tian Shan and western part of the Tarim Basin seem to continue to at least $300 \mathrm{~km}$ depth (Structure 4 in Figs. 8a-d and 9c). In this depth range, no prominent high wavespeed feature is detected beneath the Tarim Basin, but the resolution beneath Tarim Basin is relatively poor. The shallow mantle beneath the Junggar Basin is marked by high $P$ wavespeeds propagation (Structure 5 in Fig. $8 \mathrm{~b}-\mathrm{d}$ ). Fig. 9a suggests that this structure may be dipping to the south. 


\subsubsection{Mantle structure beneath the Archean cratons}

Beneath the Sino-Korean Craton the most prominent feature is the high-velocity root extending down to $200 \mathrm{~km}$ beneath the Archean nucleus of the Ordos Basin (Structure 6 in Figs. 8a-d and 9b and e). This anomaly seems to be confined within the Ordos Basin boundary. Another high-velocity root, extending down to $200 \mathrm{~km}$, underlies the eastern half of the Sichuan Basin (structure 7 in Figs. 8a-c and 9c). Below 200 km, this high-velocity root fades and changes to slow velocity structures. The resolution in the Sichuan and Ordos Basin is high (Fig. 6.2 and 6.3), so the high-velocity roots are not artifacts. Eastern migration of high-velocity root beneath the Sichuan Basin is probably effected by the collision between Indian and Eurasia plates. A large scale high-velocity anomaly appears in transition zone $(410-660 \mathrm{~km})$ beneath the Yangtze Craton (structure 8 in Figs. 8f-g and 9c and d) and the resolution in the transition zone is good (Fig. 6.5-6.8).

\subsubsection{South East China, Hainan Island}

Beneath Southern and Southeastern China, and beneath Hainan Island, in particular, the $P$ velocity is very low. At shallow depths the slow anomaly may connect westward, across the Youjiang Block, to the low wavespeeds beneath the Red River fault and the southeastern part of the Songpan Ganzi Foldbelt (Fig. 8a-c). At larger depth, a pronounced slow velocity feature is
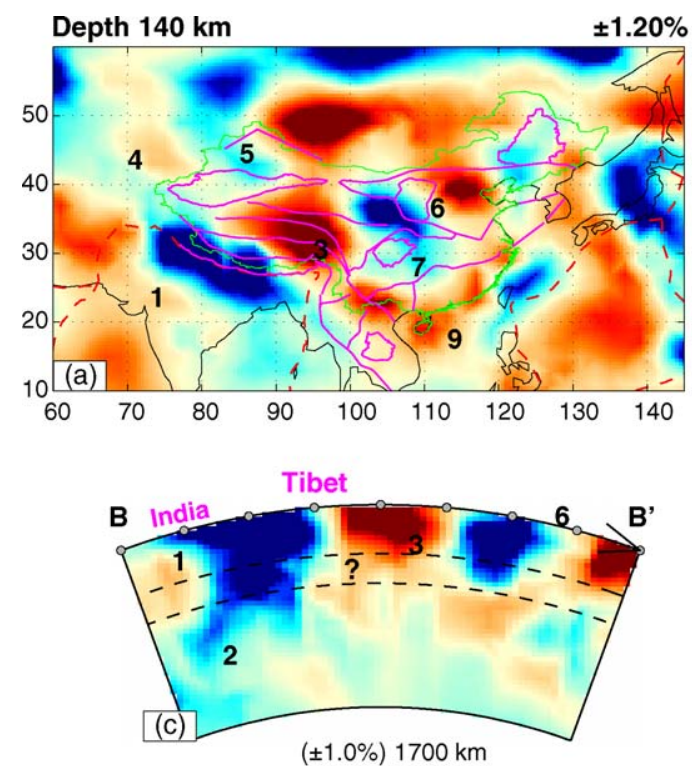

slow detected beneath the Hainan Island and the southern coast of China (structure 9 in Figs. 8d-g and 9d and e). Near $660 \mathrm{~km}$ depth, the wavespeed is not significantly different than the reference wavespeed according to ak135 (Figs. 8h and 9d and e), in the top of the lower mantle a slow velocity feature appears again. This deeper structure is much weaker than the upper mantle and transition zone anomalies, and it is not distinctly slower than nearby slow anomalies. Other studies have argued for a lower mantle origin of the Hainan structure (e.g., Montelli et al., 2004), but the observations presented here suggest that the most prominent part is confined to the upper mantle and transition zone.

\subsection{Comparison to the other global model in the region}

The model by Montelli et al. (2004) is more similar to our results than any other $P$-models that are publicly available. For this comparison we use their latest model (Montelli et al., in preparation), which has a different crust correction and, therefore, a better upper mantle structure than the one used for their 2004 publication. Fig. 10a and b depicts the anomalies at 140 and $400 \mathrm{~km}$ depth, and in Fig. 10c and d we show it for cross-sections $\mathrm{BB}^{\prime}$ and $\mathrm{DD}^{\prime}$. The long wavelengths patterns agree quite well, although there are substantial differences in amplitude (with our amplitudes almost certainly too low). At
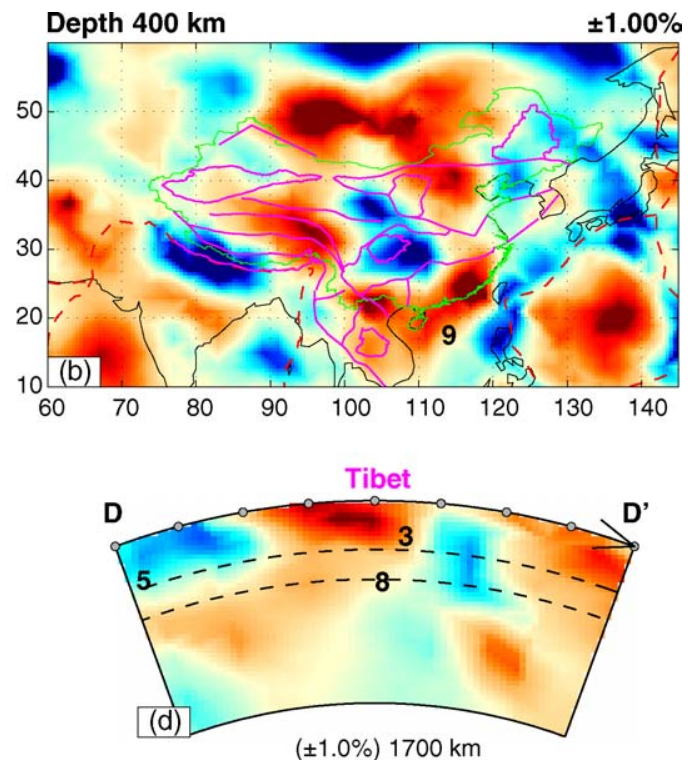

fast

Fig. 10. (a and b) Lateral $P$ wavespeeds perturbation of model from Montelli et al. (in preparation) at 140 and $400 \mathrm{~km}$ depth. (c and d) Vertical cross-sections along $\mathrm{BB}^{\prime}$ and $\mathrm{DD}^{\prime}$. 
shallow depth (Figs. 8b and 10a) we recognize similar fast anomalies beneath the boundary of Indian and Eurasian plates, north-eastern and central China, and to the north of Japan, and slow anomalies beneath the Tibetan Plateau, Hainan Island, and the coast of the South China Sea and to the south of Japan. At larger depth (Figs. 8e and 10b) both models shows fast anomalies around western Pacific plate boundaries, but differences occur that could be due to the different types of regularization employed in these studies. These difference merit further investigation, but since our main interest is in the sub continental mantle this is beyond the scope of this paper. On smaller length scales our model reveals more detail than the model by Montelli et al., which we attribute in part to our use of $\mathrm{ABCE}$ data and a higher resolution model for regional variations in crust structure.

\section{Discussion}

\subsection{The seismic evidence for subduction of Indian lithosphere}

The regional tomographic image of the upper mantle beneath central Tibet from the INDEPTH array has revealed a subvertical high-velocity zone from 100 to $400 \mathrm{~km}$ depth (Tilmann and Ni, 2003), which has been interpreted as the downwelling Indian lithosphere. This regional image covers the area from $29^{\circ} \mathrm{N}$ to $33.5^{\circ} \mathrm{N}$, and therefore does not completely image the whole underthrusting Indian lithosphere beneath the Himalayan Frontal Thrust and the Tibetan plateau. In our model, the high wavespeeds associated with what is presumably subducted lithosphere is clearly visible beneath the boundary of Indian and Eurasian plates at 140 and $200 \mathrm{~km}$ depths (structure 1 in Fig. 8b and c). At larger depths, it trends further northward and mainly underlies beneath the western part of Himalayan Block and Lasha block (Fig. 8d and e). This is also visible in $\mathrm{AA}^{\prime}$ (Fig. 9a). Although the relatively poor resolution beneath the northern Tibet leaves some room for alternate interpretations, our images suggest that the Indian lithosphere subducts from the foreland basin and underlies only the southwestern margin of the Tibet Plateau (thick blue line in Fig. 1), implying that much of the Tibet Plateau is not underlain by Indian but by Asian lithosphere (Tapponnier et al., 2001). This conclusion may be refined by analysis of the data from the MIT-CIGMR and Lehigh-CIGMR arrays, but if confirmed it has important implications for evolutionary models of the Tibetan plateau. The southward dipping high-velocity structure 2 in the lower mantle (Fig. 9a and b), interpreted as Neo-
Tethys oceanic lithosphere (van der Hilst et al., 1997; Van der Voo et al., 1999; Replumaz et al., 2004), seems to be separated from the subducted Indian lithosphere as it sinks below $660 \mathrm{~km}$ discontinuity, but this relationship will be subjected to further study.

\subsection{Fast velocity structure within the $T Z$ (410-660 km) beneath Yangtze Craton}

Our images show that there is a significant highvelocity anomaly beneath the Yangtze Craton in the transition zone (structure 8 in Fig. 8f-h, Fig. 9c and d), which spans almost $2000 \mathrm{~km}$ from northeast to southwest (Fig. 8f). The high resolution at this depth ensures that this fast velocity anomaly is not artifacts. This largescale high velocity structure may have a complex origin. The eastern part of these anomalies has been well documented in tomographic studies (e.g., van der Hilst et al., 1991; Fukao et al., 1992) and has been interpreted as "slab deflection" at the $660 \mathrm{~km}$ discontinuity as a result of slab roll back ocean ward (van der Hilst and Seno, 1993). The strong anomalies in the transition zone east of $\sim 120^{\circ} \mathrm{E}$ can probably be explained as the subducted ocean lithosphere of the western Pacific and Philippine Sea plates (Fig. 8f and g). It has been suggested that also the western part of the anomaly, between $\sim 100^{\circ} \mathrm{E}$ and $\sim 120^{\circ} \mathrm{E}$, has been produced by subduction. Lebedev and Nolet (2003) interpreted the high $S$-wave velocity beneath the Sino-Korean Craton as the subducted continental lithosphere of the Yangtze Craton beneath the Sino-Korean Craton. But perhaps the anomaly between $\sim 110^{\circ} \mathrm{E}$ and $\sim 120^{\circ} \mathrm{E}$ is related in part to the Philippine Sea subduction and the anomaly between $\sim 100^{\circ} \mathrm{E}$ and $\sim 110^{\circ} \mathrm{E}$ might be associated with the eastward subduction of the Indian plate. We thus suggest that the explanation of this transition zone structure may involve other subduction systems than subduction of continental lithosphere alone.

\subsection{Slow velocity structure beneath Eastern Tibet and South China Sea}

In the image of the upper mantle beneath eastern Tibet, the most prominent feature is the large-scale low velocity structure (structure 3 in Figs. $8 b$ and $c$ and $9 b-d$ ) in the depth above $200 \mathrm{~km}$. This structure is probably not an artifact of the thick crust since this contribution is corrected for, although it is possible that the crustal velocities are even slower than in the crustal model used for the correction. Preliminary results of receiver function and surface wave analysis of the MIT-CIGMR array data suggest the presence of slow velocity channels in 
the crust below the Sichuan and Yunnan provinces (van der Hilst et al., 2005). The location of slow wave propagation also coincided with areas of local volcanism and high heat flow; for instance, the $P$ wavespeed beneath the Tengchong volcano $\left(25^{\circ} \mathrm{N}, 98^{\circ} \mathrm{E}\right)$, one of the few recently active volcanoes in mainland China, is anomalously low. Interestingly, this is also the area where the lower crust is thought to be sufficiently hot to undergo large-scale horizontal flow (Clark and Royden, 2000).

Our preliminary results suggest that the low wavespeeds are not confined to the crust but extend much deeper into the upper mantle. The slow velocity asthenospheric mantle beneath eastern Tibet is perhaps involved in large-scale extrusion driven by the IndianEurasian collision. Alternatively, it may be related to processes further to the southeast. The large low velocity anomaly beneath Hainan Island and the south coast of China extends down to $660 \mathrm{~km}$ (structure 9 in Figs. 8c-g and $9 \mathrm{~d}$ and e) may represent a regional counter flow in response to subduction beneath nearby convergent margins. The images are suggestive of a connection between this structure and those in the shallow mantle beneath eastern Tibet (Fig. 8c). This intriguing spatial relationship is a subject of further study since it may suggest a relationship between the tectonics of eastern Tibet and mantle processes beneath the Hainan Island and South China Sea. If corroborated by further study, this connection would have major implications for our understanding of the geological history of the Tibetan plateau.

\section{Conclusions}

We have combined different seismic data sets and implemented a crustal correction in order to improve the tomographic imaging of the upper mantle beneath SE Asia. The images reveal significant heterogeneity in the upper mantle. First, high-velocity crustal roots ( $\sim 200 \mathrm{~km}$ in thickness) are observing beneath most of the Precambrian Basins (Ordos Basin, Sichuan Basin, and Songliao Basin). Second, our results suggest that only the southwest part of the Tibetan plateau is underlain by lithospheric mantle involved in the subduction of the Indian plate. This implies that most of upper mantle beneath the Tibetan plateau is primarily of Asian origin, in agreement with, for instance, Tapponnier (2001). However, better resolution is required to establish the spatial and temporal relationship between the shallow and deep slabs. Subducted Indian lithosphere is detected to $\sim 400 \mathrm{~km}$ depth and may be detached from the sinking ocean slab in the lower mantle. $P$-wave velocity is very slow beneath most of eastern Tibet where the lower crust is thought to be sufficiently hot to undergo large-scale flow (Clark and Royden, 2000). This slow anomaly may extend across the western boundary of the Yangtze Craton and connect with the low velocity structures deeper in the mantle beneath the Youjiang Block and Hainan Island. If confirmed by further study, our results pertaining to the subduction of Indian lithosphere and the possible connection between shallow mantle structures beneath eastern Tibet and the south coast of China may change views about the tectonic evolution of SE Asia.

\section{Acknowledgements}

We are indebted to Bob Engdahl for his ongoing research on the EHB dataset. We are also grateful to Raffaella Montelli for kindly providing us her new global model and to Youshun Sun for his 3D crust model. We benefited from the constructive discussion with Stéphane Rondenay, Bradford Hager, Leigh Royden, Clark Burchfiel, and Sergei Lebedev. We thank an anonymous reviewer for constructive comments, which have helped us improve the manuscript. This work was funded by NSF grant 6892042 of Collaborative Research in Eastern Tibet and AFRL grant FA8718-04-C-0018.

\section{References}

Abers, G.A., Roecker, S.W., 1991. Deep-structure of an arc-continent collision: Earthquake relocation and inversion for upper mantle $\mathrm{P}$ and S wave velocities beneath Papua New Guinea. J. Geophys. Res. 96, 6379-6401.

Bassin, C., Laske, G., Masters, G., 2000. The current limits of resolution for surface wave tomography in North America. EOS Trans. AGU 81, F897.

Bijwaard, H., Spakman, W., Engdahl, E.R., 1998. Closing the gap between regional and global travel time tomography. J. Geophys. Res. 103, 30055-30078.

Boschi, L., Ekström, G., 2002. New images of the Earth's upper mantle from measurements of surface wave phase velocity anomalies. J. Geophys. Res. 107 (B4), 2059.

Bolton, H., Masters, G., 2001. Travel times of P and S from global digital seismic networks: implication for the relative variation of $\mathrm{P}$ and S velocity in the mantle. J. Geophys. Res. 106, 13527-13540.

Clark, M.K., Royden, L.H., 2000. Topographic ooze: building the eastern margin of Tibet by lower crustal flow. Geology 28, 703-706.

Debayle, E., Kennett, B., Priestley, K., 2005. Global azimuthal seismic anisotropy and the unique plate-motion deformation of Australia. Nature 433, 509-512.

DeMets, C., Gordon, R.G., Angus, D.F., Stein, S., 1990. Current plate motions. Geophys. J. Int. 101, 425-478.

Ekström, G., Tromp, J., Larson, E., 1997. Measurements and global models of surface wave propagation. J. Geophys. Res. 102, $8137-8157$.

Engdahl, E.R., van der Hilst, R.D., Buland, R., 1998. Global teleseismic earthquake relocation with improved travel times and procedures for depth determination. Bull. Seism. Soc. Am. 88, 722-743. 
Friederich, W., 2003. The S-velocity structure of the East Asian mantle from inversion of shear and surface waveforms. Geophys. J. Int. $153,88-102$.

Fukao, Y., Obayashi, M., Inoue, H., Nenbai, M., 1992. Subduction slabs stagnant in the mantle transition zone. J. Geophys. Res. 97, 4809-4822.

Hearn, T., Wang, S., Ni, J., Xu, Z., Yu, Y., Zhang, X., 2004. Uppermost mantle velocities beneath China and surrounding regions. J. Geophys. Res. 109 (B11), 301.

Huang, J., Zhao, D., Zheng, S., 2002. Lithospheric structure and its relationship to seismic and volcanic activity in southwest China. J. Geophys. Res. 107 (B10), 2055.

Kárason, H., van der Hilst, R.D., 2000. Constraints on mantle convection from seismic tomography. In: M.A. Richards, R. Gordon, R.D. van der Hilst (Eds.). History and Dynamics of Plate Motion. Am. Geophys. Union, Geophys. Monogr. Ser., 121, 277-288.

Kárason, H., van der Hilst, R.D., 2001. Tomographic imaging of the lowermost mantle with differential times of refracted and diffracted core phases (PKP Pdiff). J. Geophys. Res. 106, 6569-6587.

Kárason, H., 2002. Constrains on mantle convection from seismic tomography and flow modeling, Ph.D. thesis, MIT.

Kennett, B.L.N., Engdahl, E.R., Buland, R., 1995. Constrains on seismic velocities in the Earth from travel times. Geophys. J. Int. 122, $108-124$.

Kind, R., Ni, J., Zhao, W., Wu, J., Yuan, X., Zhao, L., Sandvol, E., Reese, C., Nabelek, J., Hearn, T., 1996. Mid-crust low velocity zone beneath the southern Lhasa block: Results from the INDEPTH-II earthquake recording program. Science 274, 1692-1694.

Kind, R., Yuan, X., Saul, J., Nelson, D., Sobolev, S.V., Mechie, J., Zhao, W., Kosarev, G., Ni, J., Achauer, U., Jiang, M., 2002. Seismic Images of crust and upper mantle beneath Tibet: evidence for Eurasian plate subduction. Science 298, 1219-1221.

Kosarev, G., Kind, R., Sobolev, S.V., Yuan, X., Hanka, W., Oreshin, S., 1999. Seismic evidence for a detached Indian lithospheric mantle beneath Tibet. Science 283, 1306-1309.

Lebedev, S., Nolet, G., 2003. Upper mantle beneath Southeast Asia from S velocity tomography. J. Geophys. Res. 108, 2048-2074.

Lebedev, S., Nolet, G., Meier, T., van der Hilst, R., 2005. Automated multimode inversion of surface and S waveforms. Geophys. J. Int. $162,951-964$

Li, Z.X., Tectonic history of the major East Asian lithosphere blocks since the mid-Proterozoic. In: Flower M. et al. (Eds.). Mantle Dynamics and Plate Interactions in East Asia, Geodyn. Ser., 27, 211-243.

Liang, C.T., Song, X.D., Huang, J.L., 2004. Tomographic inversion of Pn travel times in China. J. Geophys. Res. 109 (B11), 304.

Molnar, P., Tapponnier, P., 1975. Cenozoic tectonics of Asia: effects of a continental collision. Science 189, 419-426.

Montelli, R., Nolet, G., Dahlen, F.A., Masters, G., Engdahl, E.R., Hung, S.H., 2004. Finite-frequency tomography reveals a variety of plumes in the mantle. Science 303, 338-343.

Northrup, C., Royden, L., Burchfiel, B., 1995. Motion of the pacific plate relative to Eurasia and its potential relation to Cenozoic extension along the eastern margin of Eurasia. Geology 23, 719-722.

Paige, C.C., Saunders, M.A., 1982. LSQR: an algorithm for sparse linear equations and sparse least squares. ACM Trans. Math. Soft. $8,43-71$.

Replumaz, A., Kárason, H., van der Hilst, R.D., Besse, J., Tapponnier, P., 2004. 4-D evolution of SE Asia's mantle from geological reconstructions and seismic tomography. Earth Planet. Sci. Lett. $211,103-115$.
Rapine, R., Tilmann, F., West, M., Ni, J., 2003. Crustal structure of northern and southern Tibet from surface wave dispersion analysis. J. Geophys. Res. 108 (B2), 2120, doi:10.1029/2001JB000445.

Shapiro, N.M., Ritzwoller, M.H., 2002. Monte-Carlo inversion for a global shear-velocity model of the crust and upper mantle. Geophys. J. Int. 151, 1-18.

Sol, S.J., Meltzer, A., Zurek, B., Zhang, X., Zhang, J., 2004. Insight into the lithospheric structure and deformation in Eastern Tibet from splitting and travel time variations of core phases, Eos Trans. AGU, 85(47), Fall Meet. Suppl., Abstract, T31A-1279.

Sun, Y., Li, X., Kuleli, S., Morgan, F.D., Toksöz, M.N., 2004. Adaptive moving window method for 3D P-velocity tomography and its application in China. Bull. Seism. Soc. Am. 94, 740-746.

Tapponnier, P., Molnar, P., 1977. Active faulting and tectonics in China. J. Geophys. Res. 82, 2905-2930.

Tapponnier, P., Zhiqin, X., Roger, F., Meyer, B., Arnaud, N., Wittlinger, G., Jingsui, Y., 2001. Oblique stepwise rise and growth of the Tibet Plateau. Science 294, 1671-1677.

Tilmann, F., Ni, J., 2003. Seismic imaging of the downwelling Indian lithosphere beneath central Tibet. Science 300, 1424-1427.

Trampert, J., Woodhouse, J., 1995. Global Phase-velocity maps of Love and Rayleigh waves between 40 and 150 s. Geophys. J. Int. 122, 675-690.

van der Hilst, R.D., Engdahl, E.R., Spakman, W., Nolet, G., 1991. Tomographic imaging of subducted lithosphere below northwest Pacific island arcs. Nature 353, 37-43.

van der Hilst, R.D., Seno, T., 1993. Effects of relative plate motion on the deep structure and penetration depth of slabs below the Izu-Bonin and Mariana island arcs. Earth Planet. Sci. Lett. 120, 395-407.

van der Hilst, R.D., Widiyantoro, S., Engdahl, E.R., 1997. Evidence for deep mantle circulation from global tomography. Nature 386, 578-584.

van der Hilst, R.D., Chen, Z., Li, C., Lev, E., Xu, L., Yao, H., 2005. Crust and Upper Mantle Structure Beneath Sichuan/Yunnan Provinces, SW China: Preliminary Results of a Joint MIT-CIGMR Broad-Band Seismometry Project. Trans. Am. Geophy. Un. Spring Meeting, Abstract, S41A-01.

Van der Voo, R., Spakman, W., Bijwaard, H., 1999. Tethyan subducted slabs under India. Earth Planet. Sci. Lett. 171, 7-20.

Waldhauser, F., Lippitsch, R., Kissling, E., Ansorge, J., 2002. Highresolution teleseismic tomography of upper-mantle structure using an a priori three-dimensional crustal model. Geophys. J. Int. 150, 403-414.

Wang, C.Y., Chan, W., Mooney, W., 2003. Three-dimensional velocity structure of crust and upper mantle in southwestern China and its tectonic implications. J. Geophys. Res. 108 (B9), 2442, doi:10.1029/2002JB001973.

Weidle, C., Widiyantoro, S., CALIXTO Working Group, 2005. Improving depth resolution of teleseismic tomography by simultaneous inversion of teleseismic and global $P$-wave travel time data: application to the Vrancea region in Southeastern Europe. Geophys. J. Int. 162, 811-823.

Widiyantoro, S., van der Hilst, R.D., 1997. Mantle structure beneath Indonesia inferred from high-resolution tomographic imaging. Geophys. J. Int. 130, 167-182.

Widiyantoro, S., van der Hilst, R.D., 1996. Structure and evolution of lithospheric slab beneath the Sunda arc, Indonesia. Science 271, 1566-1570.

Zhang, Z.M., Liou, J.G., Coleman, R.G., 1984. An outline of the plate tectonics of China. Geol. Soc. Am. Bull 95, 295-312. 